Two euroversals in a global perspective : auxiliation and alignment

\author{
Loporcaro, M
}

DOI: https://doi.org/10.1515/9783110238068.55

Posted at the Zurich Open Repository and Archive, University of Zurich

ZORA URL: https://doi.org/10.5167/uzh-51263

Book Section

Published Version

Originally published at:

Loporcaro, M (2011). Two euroversals in a global perspective : auxiliation and alignment. In: Siemund, P. Linguistic Universals and Language Variation. Berlin: De Gruyter Mouton, 55-91.

DOI: https://doi.org/10.1515/9783110238068.55 


\title{
Two euroversals in a global perspective: auxiliation and alignment ${ }^{1}$
}

\author{
Michele Loporcaro
}

\begin{abstract}
A number of studies in linguistic typology over the past few years have concentrated on what have come to be called 'euroversals'. In this paper, I shall examine two of them, viz. accusative alignment and the occurrence of a 'have'/'be' alternation in perfective auxiliation. Focusing on Romance dialects, I will show that thorough inspection of dialect variation in (a subset of) the languages of Europe provides crucial insights that have escaped so far the attention of typologists who dealt with these topics. The main results are that, firstly, alternation in perfective auxiliation is not accusatively aligned and, hence, the two euroversals at issue are mutually contradictory; and that, secondly, variation and change in perfective auxiliation across time and space in Romance reflects a shift in the alignment properties of the varieties at issue. More generally, the moral of the present discussion is that serious consideration of dialect variation is a necessary precondition for dispelling the commonplace that represents Europe as a rather dull linguistic landscape with very little structural diversity.
\end{abstract}

Keywords: alignment (accusative/nominative vs. active/inactive), dialect variation, euroversals, perfective auxiliary, Romance, unaccusativity

\section{Introduction}

A growing body of research in linguistic typology on the languages of Europe has pointed to several shared features, sometimes gathered under the Whorfian label 'Standard Average European' (cf. Whorf 1956: 138; Haspelmath 1998, 2001). These features, partly stemming from common

1 This paper is part of a research project on "Romance comparative syntax in a typological perspective" (http://www.research-projects.uzh.ch/p5704.htm). Thanks to the audience at the Hamburg workshop for comments on the oral presentation, as well as to Peter Siemund and one anonymous referee for helpful comments on a first draft. Usual disclaimers apply. 
(Indoeuropean) inheritance, partly ascribable to a convergence within a Sprachbund, have been called euroversals, defined by van der Auwera (1998: 813) as "claims that are to hold of all or most of the languages of Europe".

In this paper, I will pick up two euroversals from van der Auwera's list, viz. euroversals (iv), "use of 'have' and 'be' as auxiliaries", and euroversal (viii), "accusativity" (i.e. accusative alignment). ${ }^{2}$ I will consider some current analyses - by both functionally oriented typologists and generative grammarians - of the linguistic phenomena that substantiate these euroversals, in order to demonstrate a) that the two euroversals are related, but this relation becomes apparent only given the appropriate theoretical assumptions (i.e. assuming what has come to be called the 'Unaccusative Hypothesis'); b) that once these appropriate assumptions are made, it turns out that in-depth analysis of the former of the two euroversals mentioned (euroversal (iv)) strongly suggests that euroversal (viii) has to be relativized); and finally, c) that to realize this, thorough consideration of dialect variation is crucial.

This will be illustrated with evidence from Romance, although the conclusions reached here carry over to all European language varieties displaying a bipartite system of perfective auxiliation.

More generally, the results of my discussion should be of interest for linguistic typology as such. This is so not only because of the (ultimately sociological) fact that the literature on euroversals happens to have been nurtured by leading linguistic typologists. A more serious reason for the typological import of the present discussion stands out clearly as soon as one considers the quite different status of the two euroversals under discussion. While euroversal (iv) is a rather parochial trait of European languages (cf. section 2.1 and note 3 ), euroversal (viii) concerns (one of the possible values of) a universal of human language, since all languages of the world make decisions, one way or other, as to how to encode subject and object properties.

The paper is organized as follows. In section 2 I shall briefly introduce (Romance) perfective auxiliation along with some received ideas about it, in both the functional-typological and the generative lines of research. In section 3 I shall show why auxiliation has to be understood against the background of alignment. Section 4 compares the formal treatment of

2 As will become apparent in table (10) below, 'accusative' alignment is shorthand for accusative/nominative alignment, like 'ergative' alignment stands for ergative/absolutive: in both cases, the unmarked option in the marking system is mentioned to refer to the system as a whole. 
Italian auxiliation first put forward by Perlmutter (1989) and elaborated on in the present paper with some alternative semanticist accounts. Section 5 brings dialect variation into the picture, showing that the approach to auxiliation defended here, unlike competing treatments, is able to provide an elegant analysis on the whole Romance scale. This analysis accounts for the distribution of perfective auxiliaries in all Romance dialects in both their modern and their medieval stages. The concluding remarks (section 6) highlight the significance of these findings from a typological perspective.

\section{Current research on perfective auxiliation}

\subsection{The functional-typological approach}

The basic empirical question is what perfective auxiliation and alignment have to do with each other. In the line of typological research on euroversals, the answer is plainly "nothing". The fact of displaying 'have' and 'be' as auxiliaries (euroversal (iv)) and the fact of displaying accusative alignment (euroversal (viii)) stand in no obvious relationship.

In fact, the many studies devoted to auxiliation in the functional-typological approach (e.g. Harris and Ramat 1987; Heine 1993; Thieroff 2000; Haspelmath 2001; Kuteva 2001; Heine and Kuteva 2006; Drinka 2003, 2007) never mention alignment in this connection. The main focus of these studies is on the grammaticalization cline that leads a lexical predicate for instance, a possessive predicate, or a predicate meaning 'to hold' - to become an auxiliary. This entails a preoccupation with specific lexical morphemes (especially 'have') that is spelled out in its most explicit form by Heine and Kuteva (2006: 142): “'be'-perfects [...] are ignored here, and it would also be beyond the scope of the present treatment to study how the two constructions interact". Introducing their chapter on "possessive perfect", the authors make clear that they are excluding constructions with 'be' to focus exclusively on those with 'have' as a perfective auxiliary. The latter are interesting in themselves, because they are not so common outside Europe ${ }^{3}$, and they are studied, by Heine and Kuteva as well as by

3 Cf. the lists of languages displaying 'have' as perfective auxiliary outside Europe (Hittite hark- 'hold, have' + participle = perfect/resultative, colloquial Georgian, Hdi, a Chadic language of Northern Cameroon, Chukchi, Old Egyptian; within Indo-European, Old Indian, Old Iranian, Old Armenian) provided by Haspelmath (2001: 1495), Heine and Kuteva (2006: 141). In 
the other scholars mentioned above, especially in their relation to other verbal morphemes occurring as past tenses, such as the Simple Past (or Preterite).

This approach has many virtues and yields quite interesting generalizations. However, by considering 'have'- and 'be'-perfective periphrastics as instances of "two constructions", distinct from one another, it is doomed to miss the syntactic essence of 'have'/'be' alternations. With its focus on the nature and development of specific verbal lexical morphemes, rather than on the system of auxiliation, this kind of study is one manifestation of what is labeled in Loporcaro (2007: 175-179) a "lexical" approach to "auxiliary selection", as opposed to a "syntactic" approach to "auxiliation". Furthermore, exclusive fixation on auxiliary 'have' generates problems, starting with basic terminology, as is readily apparent from Heine and Kuteva's (2006: 143) discussion of the label "possessive perfect", which the authors use - like many other typologists - to refer to perfective periphrastics built with 'have':

We are ignoring a problem that is central to some other researchers, namely the fact that the term 'possessive perfect' is somewhat misleading. In quite a number of European languages, this construction has a meaning that has little in common with a perfect (or a present anterior) (Heine and Kuteva 2006:143).

This caveat follows from a double misunderstanding, concerning form and function, on the one hand, and synchrony and diachrony, on the other. Consider the contrast, displayed by many European languages, exemplified in (1) with the two perfective past tenses of Italian traditionally labeled 'passato remoto' vs. 'passato prossimo' by Italian grammarians:

$$
\begin{aligned}
& \text { a. function (aspect) } \\
& \text { b. form (tense) } \\
& \text { terminology (i) } \\
& \text { terminology (ii) }
\end{aligned}
$$

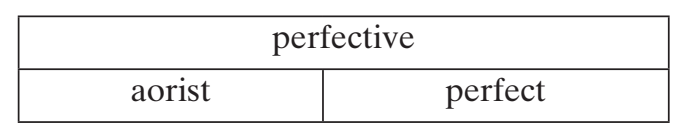

mangiai 'I ate' $\neq$ ho mangiato 'I've eaten'

\begin{tabular}{|c|c|}
\hline Simple Past & Compound Past \\
\hline Simple Perfect & Compound Perfect \\
\hline
\end{tabular}

In current studies of the verb system, these two tenses are labeled either Simple vs. Compound Past respectively (1b-i), as e.g. in Squartini and Ber-

Europe, have-perfects are attested in Albanian, Germanic, Romance, plus some Slavic languages (Macedonian, Bulgarian, Serbian/Croatian, Czech), and, outside Indoeuropean, Basque. 
tinetto (2000), or else, with an alternative (continental) terminology (1bii), Simple vs. Compound Perfect (e.g. Bertinetto 1986). In (1), Bertinetto's notational convention is adopted, capitalizing Perfect as a tense label, to distinguish it from perfect, non capitalized ((1a)), as a label for one of the subdivisions of perfective aspect, contrasting with aorist (aspectually, the two tenses differ in terms of non-inclusion/inclusion of the speech moment in the description of the verbal event). Now, the label "possessive perfect", in Heine and Kuteva's own line of research, designates a form, viz. a verb tense formed with the auxiliary 'have', (1b-ii). It cannot possibly designate a function - 'perfect', as opposed to 'aorist', (1a) - unlike claimed by Heine and Kuteva, because if it were so, the European languages displaying 'have'-perfects would turn out to have very little in common in the first place. What they all do have in common is the property of forming periphrastic past tenses with the auxiliary 'have' ((1b)), be they aspectually ((1a)) perfect (like in Standard Italian) or just perfective (like in, say, spoken French or Alemannic dialects of German). ${ }^{4}$

Therefore, the label 'possessive perfect' is not misleading at all because of "perfect". On the contrary, one may argue that it is misleading because of "possessive", since it unduly mixes synchrony and diachrony. Perfective auxiliaries, synchronically speaking, have nothing to do with possession, although precisely this is the crucial claim of many (indeed most) current analyses of auxiliaries, not only in the functionalist stream of research considered so far but also in many formally oriented studies.

\subsection{Auxiliary selection in generative grammar}

Most studies on auxiliary selection in generative grammar try to derive the properties of the perfective auxiliary 'have' (as well as 'be', in this case), from (alleged) lexical properties of possessive 'have' and copula 'be' respectively: cf. e.g. Cocchi (1995), Kempchinsky (1996), Ledgeway (1998), Manzini and Savoia $(2005,2007)$ etc. (a short selection limited to Romance). ${ }^{5}$ Lois (1990) is a paradigmatic case. She aims to explain the

4 The list of semantic differences observed among perfective periphrastics in the languages of Europe is quite long, involving not only aspectual but also Aktionsart properties, like e.g. in Portuguese (cf. Squartini 1998 for an overview of the Romance facts in this respect).

5 Kayne (1993), elaborating on an idea by Benveniste (1960), goes a step further, unifying 'have' and 'be' as both auxiliary and non-auxiliary into one single abstract category (cf. the critique in Loporcaro 2001, 2007). 
contrast between the Spanish type (in (2)), where only one perfective auxiliary occurs (haber), and the French type (3), with two auxiliaries (avoir in (3a) vs. être in (3b)):
a. transitive/unergative
Pilar ha comido (la sopa)
Pilar has eaten (the soup)
'Pilar has eaten (the soup).'
a. transitive/unergative
Marie a mange (la soupe)
Mary has eaten (the soup)
'Marie has eaten (the soup).'
b. unaccusative
Pilar ha llegado Spanish
Pilar has arrived
'Pilar has arrived.'

b. unaccusative

Marie est arrivée French
Mary is arrived
'Marie has arrived.'

According to Lois, Spanish haber generalized to all clause types, including unaccusatives ((2b)), because of a change in the lexical specification. While it was a transitive predicate in Old Spanish, like its Romance cognates (cf. the lexical specification in (4a)), it is assumed to have become intransitive in modern Spanish ((4b)):
a. $\mathrm{HABERE}^{1}=$ Fr. avoir, O.Sp. haber [+Object Case]
[+subject theta-role]
b. $\mathrm{HABERE}^{2}=\mathrm{Sp}$. haber
[-Object Case]
[unmarked subject theta- role]

This explains why haber became compatible with unaccusatives as well ((2b)). Independent evidence for this change is provided by the fact that haber was ousted by tener as a possession verb in the history of Spanish. As shown in Loporcaro (2007: 176), however, as soon as one expands the database considering dialect variation, dozens of Romance varieties crop up which are at odds with Lois' explanation of the spread of 'have' as unique perfective auxiliary. In the northern Calabrian dialect of Trebisacce, for instance, auxiliary 'have' was generalized, like in Spanish ((5ab)), even though the same verb still serves as a possessive predicate $((6))$ : have.1sG cooked.F.SG the soup.F 'I cooked the soup.'
a. ăğga kott amanestra (transitive)
b. marí a mmort
Mary.F has died.F.SG
'Mary died.'
(unaccusative) 

a. $a \check{g} \breve{g} \partial \quad n-a \quad k a i s \partial n-\mho \quad$ maira have.1SG a-F.SG house in-the sea 'I've got a house at the seaside.'
b. marí $a \quad n-a$ kassa n- ma:ra Mary.F has a-F.SG house in-the sea

'Mary has got a house at the seaside.'

Inspection of dialect variation here shows that treatments $a$ la Lois, while describing the Spanish facts and being compatible with the data from the other standard Romance languages, do not help us to understand what is going on in perfective auxiliation on a Romance scale.

\section{Auxiliation and alignment}

\subsection{A different look at (Romance) perfective auxiliation}

A line of research alternative to the ones reviewed in section 2 has proven more effective in its attempt to cope with this dialect variation and to understand the relationship between auxiliation and alignment. This alternative approach, originating with Perlmutter's $(1978,1989)$ seminal work (see also Rosen 1981 [1988], 1997; La Fauci 1988, 1989; Loporcaro 2007), elaborates on the idea that perfective auxiliaries are purely syntactic objects, as defined in (7):

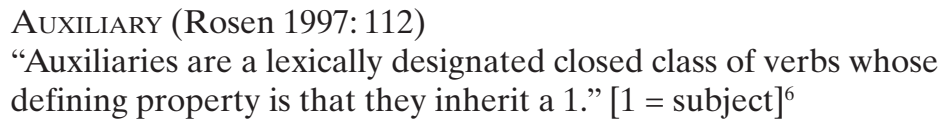

From this definition, all remaining properties of auxiliaries usually listed in typological surveys (cf. e.g. Ramat 1987: 13) follow automatically: if a predicate does not introduce a new subject into the clause, then it has no argumental grid at all and no lexical semantics of its own. Rather, it reduces to a TAM morpheme, also marking person, just like inflections in non-periphrastic finite verb forms.

6 The argument at issue is inherited from a lexical predicate, which contributes the lexical semantics and, formally, takes on non-finite verb morphology in the languages we will be dealing with here. 
Now, cross-referencing on the verb is one of the domains in which alignment properties are manifested, which brings us back to euroversal (viii), accusativity. As is well known - and can be seen in (2)-(3) - finite verb morphology shows subject agreement in both transitives and intransitives (i.e., it displays accusative alignment) throughout Romance and SAE. However, if auxiliaries also are TAM morphemes, providing finite verb morphology, auxiliary choice is also relevant for alignment, and since 'have'/'be' selection cuts across intransitives (as already shown for French in (3)), perfective auxiliation must be considered a feature which is not accusatively oriented. Rather, as will be shown in section 3.2, it is a case of active/inactive alignment.

\subsection{Alignment and the Unaccusative Hypothesis}

This is the basic typological insight underlying Perlmutter's Unaccusative Hypothesis, which assumes a structural bipartition of (monadic) intransitive constructions, as shown in (8)-(9). In (8a-b), the few initial items from the lists in Perlmutter (1978: 162) are reported, specifying that the initial argument of unaccusatives $((8 \mathrm{a}))$ is represented as an initial direct object (= initial 2), whereas that of unergatives $((8 b))$ starts out as a subject (= initial 1):
a. UnACCUSATIVE:
$\mathrm{P}\{2\} \quad$ burn, fall, drop, sink ...
(It. bruciare, cadere, affondare ...)
b. UNERGATIVE:
$\mathrm{P}\{1\} \quad$ work, play, speak, talk ...
(It. lavorare, giocare, parlare ...)

(9a-b) give the two structural representations proposed for the two subsets of intransitives by Perlmutter within RG: ${ }^{7}$

7 Relational diagrams provided in this paper conform to the representational standard first introduced by Davies and Rosen (1988). In these diagrams, 1 $=$ subject, $2=$ direct object, $3=$ indirect object, $\mathrm{P}=$ predicate, Cho = chômeur ("the relation held by a nominal that has been ousted from term status", Blake 1990: 2). Under Davies and Rosen's (1988) Predicate Union hypothesis, the chômeur relation also applies to predicates, not just to arguments (cf. 'nominal' in the original definition). Thus, when the auxiliary comes in (in the last stratum in (9a-b)), the lexical predicate goes to chômeur, in compliance with Perlmutter and Postal's (1983) Motivated Chômage Law. However, this specific technical aspect is not germane to our present discussion. To follow this 
(9)

\begin{tabular}{ccc} 
a. & \multicolumn{1}{c}{$\mathrm{P}$} \\
1 & $\mathrm{P}$ \\
\hline 1 & $\mathrm{P}$ & Cho \\
La nave è & affondata \\
'The boat sank' &
\end{tabular}

b.

\begin{tabular}{ccc}
1 & & $\mathrm{P}$ \\
\hline 1 & $\mathrm{P}$ & Cho \\
Gianni ha & lavorato \\
'John worked' &
\end{tabular}

As shown in (10), the Unaccusative Hypothesis allows for a straightforward representation of the most widespread alignment systems, including the somewhat controversial active/inactive type: 8

\begin{tabular}{|c|c|c|c|c|c|}
\hline \multirow[b]{2}{*}{ a. ergative } & & & & & \multirow{2}{*}{ relation } \\
\hline & ERG & ABS & ABS & $\mathrm{ABS}$ & \\
\hline b. active & ACT & ACT & INA & INA & $\leftarrow$ morphological \\
\hline c. accusative & NOM & NOM & NOM & ACC & $\begin{array}{l}\text { (head and/or } \\
\text { dependent) }\end{array}$ \\
\hline
\end{tabular}

Proposing the Unaccusative Hypothesis, Perlmutter (1978: 186) mentions Sapir's (1917: 73) analysis of active/inactive syntax in Amerindian languages among his sources of inspiration. ${ }^{9}$ Sapir's account, in turn, is the starting point in a research line (cf. Harris and Campbell 1995: chapter 9; Harris 1997:362) that regards the active/inactive type as a basic type, syntactically defined on a par with accusative and nominative. Alternative

discussion, previous acquaintance with the RG framework is not necessary: all relevant notions will be introduced (mostly in footnotes) as the argument proceeds.

8 As abundantly shown in the typological literature, alignment (ergative, active or accusative, plus possibly some other minor types that need not detain us here) can be signaled by either head or dependent marking (i.e. verb agreement or case marking on the NP, respectively), or by other syntactic devices including word order. For instance in Waurá (an Arawakan language of Brazil) both transitive and active intransitive subjects precede the verb, whereas inactive intransitive subjects follow it, on a par with transitive objects (cf. Dixon 1994: 77): in this case, basic word order obeys active alignment (10b).

9 Thus, it is fair to claim that the Unaccusative Hypothesis, though Perlmutter does not put it explicitly that way, is basically an hypothesis about alignment. 
views, however, consider the active/inactive type either as a mixed type - a compromise between ergative and accusative (Dixon 1994: 77) - and/or regard it as defined in purely semantic - as opposed to syntactic - terms (e.g. Mithun 1991: 542; Van Valin and La Polla 1997: 255-257).

The three-primitive system ( $\mathrm{S}, \mathrm{A}$ and $\mathrm{O}$ ) commonly adopted (after Dixon 1972) to represent grammatical relations in studies in linguistic typology, is in keeping with the idea that active/inactive alignment is not syntactically determined and/or not a basic type. Indeed, in Dixon's (1979, 1994) terminology, active/inactive alignment is relabeled "Split-S", and it is assumed that such contrasts, whenever met in the languages of the world, are not encoded syntactically but rather base on a purely semantic bipartition of intransitive verbal events in terms of "controlled" $\left(=S_{a}\right)$ vs. "non-controlled" $\left(=\mathrm{S}_{\mathrm{o}}\right){ }^{10}$ This leads to the prediction that this type of alignment must be rare among the languages of the world:

[...] for many intransitive verbs, it is difficult to decide whether they basically belong to the 'controlled' or 'non-controlled' class, i.e. it is difficult to determine whether the S NP is of subtype $\mathrm{S}_{\mathrm{a}}$ or $\mathrm{S}_{\mathrm{o}}$. Most languages avoid decisions in this area of semantic fuzziness by simply making all S like A (the accusative scheme) or all S like O (the ergative scheme). (Dixon 1994: 53-54) [emphasis added, M.L.].

This assumption was responsible for some gross misunderstandings. One case in point is Basque, which is classified as active(-inactive) by Comrie (2005:399) with respect to case-marking on the noun phrase. This is right, but contrasts with a long tradition which regards Basque as a prototypical representative of ergative alignment (cf. e.g. Aldai 2000:35 note 3; Bossong 1984:342; Brettschneider 1979:371; Dixon 1994:2,150; Eguzkitza and Kaiser 1999: 199; Manandise 1987: 320-321; Palmer 1994: 54-55, 104-105; Ura 2000: 180,186 , etc.) ${ }^{11}$ How could this happen given that ergative and active are two completely different kinds of alignment, and Basque has indeed active, not ergative, case marking? Arguably, an attitude à la Dixon played a role here, leading typologists to the wrong expectation that active alignment should be rare, as well as to wrong analyses of active systems in terms of ergative.

10 As observed by Harris (1997: 367), the assumption of a $S_{a}$ vs. $S_{0}$ split is inconsistent with Dixon's definition of $\mathrm{S}$ (on a par with $\mathrm{A}$ and $\mathrm{O}$ ) as a primitive.

11 Bittner and Hale (1996: 26-27) call Basque "ergative-active" (as opposed to, say, Dyirbal, which is ergative in their terminology). 


\subsection{Unaccusativity: syntax and semantics}

Active alignment is indeed not at all infrequent, and the Unaccusative Hypothesis had the merit of revealing that active-inactive features are well represented cross-linguistically, even at the core of SAE. Note that this is only true under a view of Unaccusativity à la Perlmutter (1989) (or Rosen 1984), which regards unaccusativity as an autonomous syntactic property, correlated with - but not reducible to - semantic factors like telicity or agentivity. As shown with the adverbial tests in the sentences in (11a-b), unaccusatives are indeed more often telic than non-telic, whereas unergatives are more often non-telic: ${ }^{12}$
a. La nave è affondata the boat is sunk
in/*per tre
in/for three hours
'The boat sank in/*for three hours.' (= TELIC; argument PATIENT)
b. Gianni ha lavorato per/*in tre ore UNERGATIVE
Gianni has worked for/in three hours
'Gianni worked for/*in three hours.' (= NON-TELIC; argument AGENT)

Symmetrically, unergatives are mostly agentive. However, under this view these are just statistical correlations, although admittedly quite robust.

Much like for auxiliation, however, also in the case of unaccusativity, the position just summarized, which acknowledges the autonomy of syntax, has not been on fashion lately. Most on-going research, both in the functionalist and the formalist camps, takes a reductionist stance on unaccusativity, either claiming that it is semantically determined and syntactically encoded (e.g. Rappaport Hovav and Levin 2000; Van Hout 2004: 61 etc.) or even denying that a syntactic representation of unaccusativity of the sort proposed by Perlmutter $((9 a-b))$ is needed at all (e.g. Van Valin 1990; Dowty 1991; Lieber and Baayen 1997; Van Valin and La Polla 1997; Bentley 2006 etc.).

In what follows, I will show that the semanticist-reductionist approach does not provide a suitable alternative to accounts of auxiliation that rely on a(n autonomous) syntactic view of unaccusativity. Only under this syntactic approach, I shall argue, a) it is possible to make sense of dialect variation for a host of syntactic properties throughout Romance and

12 As apparent from (11a-b), time-frame adverbials (in $\mathrm{x}$ time) are compatible with telic predicates, whereas time-span adverbials (for $\mathrm{x}$ time) combine freely with non-telic ones, not vice versa. 
beyond; ${ }^{13}$ and $b$ ) it becomes possible to grasp the typological significance of these properties in a cross-linguistic perspective.

\section{Assessing syntactic vs. semantic accounts of Romance perfective auxiliation}

The most widely discussed property among the manifestations of unaccusativity is no doubt perfective auxiliation. ${ }^{14}$ For Italian, a very influential account was put forward by Sorace (2000), who assumes the auxiliary selection hierarchy in (12), defined as "an empirical generalization that identifies the notion of 'telic change' at the core of unaccusativity and that of 'atelic non-motional activity' at the core of unergativity" (Cennamo and Sorace 2007: 67-68): $:^{15}$

13 The list of other syntactic properties sensitive to unaccusativity includes, among others, past participle agreement in perfective periphrastics, ne-pronominalization, the marking of the nuclear argument under causativization, the syntax of participial absolutes and attributive participles, etc. For all these properties, an economic formalization became first available under the Unaccusative Hypothesis, given the different structural representations of the two subsets of intransitives in (9a-b). Viewed from this angle, all these properties can be subsumed under the heading active/inactive alignment.

14 There has been a flood of semanticist accounts of Italian (and Italo-Romance) perfective auxiliary choice, including e.g. Parisi (1976), Centineo (1986), Van Valin (1990), Kishimoto (1996: chapter 4.2), Sorace (2000), Cennamo (2001), etc.

15 In more recent work, Sorace (2008) concludes that "like other phenomena, split intransitivity seems to involve two sides: a syntactic one and an interface one". This seems to leave open the possibility for a lexical encoding of unaccusativity à la Perlmutter. Nevertheless, Sorace (2008) still maintains her critique of projectionist approaches to unaccusativity (see note 16), as in such approaches "the lexicon is burdened with double entries and ad-hoc lexical rules" (to account for intransitives with double auxiliation).

Other recent psycholinguistic studies, like Friedmann et al. (2008: 370), support the syntactic view of unaccusativity. The results provide evidence "that it is only the verb's underlying argument structure - whether it is unergative, unaccusative, or transitive - that is used, initially, during parsing routines". Since "unaccusatives [...] reactivate their subjects after the verb whereas unergatives do not", there must be a categorical contrast in representation between the two subclasses of intransitives. 


$\begin{array}{lll}\text { Sorace (2000): } & \text { CHANGE OF LOCATION } & >\text { categorical BE selection } \\ \text { Auxiliary selection } & \text { change of state } & > \\ \text { hierarchy (ASH) } & \begin{array}{l}\text { continuation of state } \\ \text { existence of state }\end{array} & > \\ & \begin{array}{l}\text { uncontrolled process } \\ \text { motional process }\end{array} \\ & > \\ \text { NON-MOTIONAL PROCESS } & >\text { categorical HAVE selection }\end{array}$

The hierarchy accounts for the categorical selection of 'be' or 'have' with verbs at the two poles of the continuum, as well as for the vacillation with those in the central part of the scale. In this perspective, semantics determines auxiliary selection, one of the principal manifestations of unaccusativity. This is clearly stated in the conclusion of Cennamo and Sorace's (2007: 93-94) study of auxiliary selection in Paduan:

[...] four semantic parameters interact in different ways and to a different extent in determining auxiliary selection with these verb classes/patterns: - the degree of telicity of the verb/predicate; - the degree of control and affectedness of the subject; - the conceptualization of the situation described by the verb as either an activity or a result state; - the notions of internal and external causation.

In the syntactic approach, on the contrary, auxiliation is not determined by the semantics and vacillation in auxiliary choice with many predicates (especially those in the central positions in the hierarchy in (12)) is interpreted as the manifestation of a double syntactic construction option, which follows in turn from a lexical specification that allows both an unaccusative and an unergative construction: e.g. risuonare 'to resound' $\{\mathrm{P}, 1\}$ (unergative) or $\{\mathrm{P}, 2\}$ (unaccusative). ${ }^{16}$

16 The syntactic approach defended here bears some resemblance to what are sometimes labeled "projectionist approaches" to unaccusativity (Levin and Rappaport Hovav 2005: 189-193). However, the correspondence is blurred by the semanticist twist that the label is given in work on the topic by Levin and Rappaport Hovav or Sorace (note 15), among others. On the one hand, the claim that "verbs have structured lexical entries which register the number and types of arguments they take" (Levin and Rappaport Hovav's 2005: 33 note 2 summary of Chomsky's 1981 Projection Principle) aptly characterizes a syntactic approach to unaccusativity à la Perlmutter (1989) and Rosen (1984). On the other hand, "the assumption that the complement structure of a verb is determined by its semantics", also ascribed to "projectionist approaches" by Levin and Rappaport Hovav (2005: 189), is blatantly at odds with the definition of unaccusativity endorsed by Rosen and Perlmutter. 
Apart from these cases of variation in the lexical specification, in the syntactic approach unaccusative vs. unergative predicates are represented structurally in two different ways, and these representations are then scanned by Perlmutter's auxiliary selection rule (13):

$$
\begin{aligned}
& \text { Perfective auxiliation in Italian (Perlmutter 1989: 81) } \\
& \text { The perfective auxiliary is essere iff the final } 1 \text { is a 2. } \\
& \text { Otherwise the perfective auxiliary is avere. }
\end{aligned}
$$

This rule accounts, by the same token, for the occurrence of avere in unergative constructions $((9 b))$ and in transitive clauses $((14 a))$, where the subject never bears the DO relation, as well as for the selection of auxiliary essere in unaccusatives $((9 \mathrm{a}))$ and reflexives $((14 \mathrm{~b})):{ }^{17}$

$$
\begin{aligned}
& \text { a. } \begin{array}{cccc}
1 & & \mathrm{P} & 2 \\
\hline 1 & \mathrm{P} & \text { Cho } & 2
\end{array} \\
& \text { Maria ha lavato la camicia } \\
& \text { 'Mary washed the shirt.' }
\end{aligned}
$$

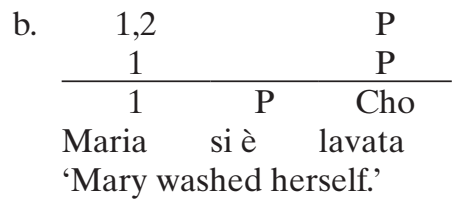

Semanticist analyses of auxiliary selection, on the other hand, cannot offer anything comparable, in terms of descriptive economy. Van Valin (1990), for instance, proposes two rules instead of one, since (15a) covers intransitives only so that, in addition, (15b) must be formulated, in order to account for auxiliation in transitives and reflexives:
a. Auxiliary Selection with intransitive verbs (Van Valin 1990: 233) "Select essere if the LS [= logical structure, M.L.] of the verb contains a state predicate".
b. Auxiliary selection for italian verbs (Van Valin 1990: 256) "Select avere if the subject is an unmarked actor (with respect to the Actor-Undergoer Hierarchy [...]), otherwise essere".

17 As seen in (14b), reflexiveness is represented in RG under the form of multiattachment: the notation 1,2 means that one and the same nominal bears two distinct grammatical relations at the same stratum. Since no nominal in a language like Italian can have both the surface properties of a subject and of a DO at the same time (in terms of e.g. basic word order, verb agreement etc.), multiattachment is resolved in the first available stratum, which results in the appearance of the reflexive clitic marker si on the verb (cf. Rosen 1981 [1988], 1982 for the technicalities concerning this formal representation of reflexives). 
Along the same lines, Bentley and Eythórsson (2003) assume no fewer than three distinct rules:

Perfect formation Rule in modern Romance (Bentley and Eythórsson 2003)

(i) if $\mathrm{V}$ is [+pronominal] $\quad>$ 'be' + past participle

(ii) a. if $\mathrm{P}$ is marked $[+\mathrm{Fn}] \quad>$ 'be' + past participle

b. elsewhere $>$ 'have' + past participle

In spite of the claim that "perfect formation involves two rules [...] in modern Romance" (Bentley and Eythórsson 2003: 468) - one for reflexives ((16i)), the other for intransitives ((16ii)) - a third rule (select avere invariably) must be posited for transitives: "It should be stressed that the rule in (22) [i.e. (16) here, M.L.] regards auxiliary selection with all intransitives, but not with transitives" (Bentley and Eythórsson 2003: 461).

Of these three disparate rules, only (16ii), applying to intransitives, is directly sensitive to the semantics, as " $\{\mathrm{Fn}\}$ is a subset of $\{\mathrm{F}\}$ including the properties which are relevant for 'be' selection in a particular language [...]: dynamicity, telicity, stativity" (Bentley and Eythórsson 2003: 460).

\section{Variation in auxiliary selection across Romance languages and dialects}

This kind of analysis is less economical than Perlmutter's even for the variety for which it is proposed, viz. modern standard Italian: it puts forward two or three unrelated rules instead of one, with no prospects of relating auxiliation to the remaining features - mentioned in note 13 sensitive to the active/inactive contrast. Under Perlmutter's view, on the contrary, this relationship can be accounted for straightforwardly. Furthermore, as soon as one considers dialect variation, the fallacy of semanticist analyses of auxiliation stands out all the more clearly.

\subsection{Sardinian and French}

In several Romance varieties, reflexives do not display a uniform auxiliary choice. In Sardinian, for instance, as shown by the Logudorese data in (17), monadic reflexives (i.e. reflexive constructions which involve only one nominal core argument, (17b-c)) pattern with unaccusatives ((17a)) in that they select 'be', whereas dyadic reflexives (i.e. reflexives in which 
two distinct nominals bear the subject and the DO relations initially, (17d)) - corresponding to Standard Italian Maria si è lavata le mani but with the opposite auxiliary choice - behave like transitives and unergatives (17e): (Capital E stands for auxiliary 'be', $\mathrm{H}$ for auxiliary 'have'.) ${ }^{18}$
a. maria es paltiða Logudorese Sardinian
Mary is left.F.SG
'Maria left.'
b. maria $z$ el bestiða
Mary REFL is washed.F.SG
'Maria washed herself.'
c. maria $z$ er risposta
Mary REFL is answered.F.SG
'Maria answered herself.' AUX E
d. maria $z$ a ssamuna:ðu zal ma:nos AUX H
Mary REFL has washed.M.SG the hands
'Maria washed her hands.'
e. maria a mmaniza:ðu (za minestra)
Mary has eaten.M.sG (the soup)
'Maria ate (the soup).'

Assuming the standard structural representations seen in $(9 a-b)$ for intransitives and (14a-b) for transitives, plain and direct reflexive - to which in (18a-b) those widely assumed for indirect reflexives, unergative and transitive, are now added - we are in a position to formulate one single rule, that accounts for perfective auxiliation in all syntactic constructions $((19)):^{19}$

18 The different syntactic constructions in (17a-e) design an implicational scale (cf. Loporcaro 2007), along which all auxiliation options found in all Romance languages and dialects can be ranged. We shall come back to this in (30), §5.4.

19 See note 17 for the representation of reflexiveness. Initial 1,3 multiattachment in (18a) depends on the predicate's argument grid, as rispondere 'to answer' selects an IO: Maria ha risposto a Gianni 'Mary answered to John'. In (18b), on the other hand, the IO depends on the DO nominal and denotes its possessor (cf. Rosen 1990). Reflexive 1,3 -> 1,2 advancement in the second stratum in both $(18 \mathrm{a}-\mathrm{b})$ complies with a hypothesis on the structural representation of indirect reflexives originally put forward by La Fauci (1988: 82-88), to which the reader is referred for the supporting arguments. (Cf. also La Fauci 1994:5360 for a discussion of those arguments more accessible to an international readership.) 
a.

\begin{tabular}{ccc}
1,3 & & $\mathrm{P}$ \\
1,2 & & $\mathrm{P}$ \\
1 & & $\mathrm{P}$ \\
\hline 1 & $\mathrm{P}$ & Cho
\end{tabular}

Maria si è risposta

'Mary answered herself.' b. $1,3 \quad \mathrm{P} \quad 2$

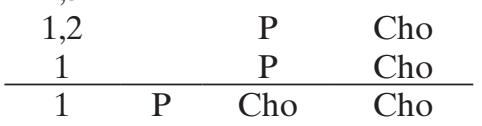

Maria si è lavata le mani

'Mary washed her own hands.'

Perfective auxiliation in Sardinian (La Fauci and Loporcaro 1993: 164)

The perfective auxiliary is $\mathrm{E}$ iff: the final 1 is the first 2 in the clause.

Otherwise the perfective auxiliary is $\mathrm{H}$.

A semanticist alternative would have no chance of being as economical as the generalization in (19) for Sardinian, let alone for the whole Romance comparative picture. For Sardinian, this is demonstrated by the fact that reflexives which belong to distinct syntactic subclasses - like e.g. si estirre 'to dress oneself' vs. si zamuna:re zal ma:nos 'to wash one's hands' - may have identical Aktionsart semantics, as shown by the telicity diagnostics in $\mathrm{x}$ time in $(20 \mathrm{a}-\mathrm{b})$ :
a. maria $z \quad \varepsilon l$ bestirða in kimbe minúttozo
Mary REFL is dressed in five minutes
'Maria dressed (herself) in five minutes.'
b. maria $z \quad$ a ssamuna:ðu zal ma:noz in kimbe minúttozo Mary REFL has washed her hands in five minutes 'Maria washed her hands in five minutes.'

Nevertheless, they display a distinct auxiliary choice: the syntax prescribes it, via the generalization (19), whereas the semantics here does not play any role whatsoever.

Note that (19) is one rule, with a positively specified option (selection of 'be') plus an elsewhere condition ("select 'have' elsewhere"), just like it is common practice in formal linguistics ever since the rise of generative phonology in the Sixties. This single rule has scope over all relevant constructions, viz. all compound tenses displaying perfective auxiliation, whatever their lexical predicate. This makes a noteworthy difference with respect to Bentley and Eythórsson's (2003) approach, discussed in section 4. There one finds one rule for reflexive verbs ((16i)), another distinct rule for intransitive verbs ((16ii)) plus a third one for transitives, whose outputs partially overlap. In a similar vein, Bentley (2006: 72) proposes what she calls "a rule" to account for perfective auxiliation in French: 
(21) Perfective operator SELECtion in French:

Select avoir 'have' unless

a. The construction is marked by se or

b. The predicate is a telic intransitive.

She herself recognizes that " $[\mathrm{t}]$ he two subrules are related in terms of a disjunction, and thus cannot be said to constitute a proper generalization", and, besides, that the two are disparate, since "one [...] is morphological, and the other semantic". Note, furthermore, that while (21b) is meant to account for the fact that in French non-telic unaccusatives like rester 'to remain' select avoir (Marie a restée 'Mary has remained'), it wrongly predicts that telic unergatives like déménager 'to move' should categorically select être. However, this is not the case, since in actual usage examples like (22a) by far outnumber those like (22b) (which are anyway open, in many a case, to an alternative stative-resultative interpretation):

a. Marie a déménagé (en une journée).
Mary has moved in one day
'Marie has moved in one day.'
b. Marie est déménagée.
Mary is moved
'Mary has moved.'

A Google search on March 18th, 2009 gives about 167000 results with 'have', 2000 of which with (graphic) participle agreement (e.g. la mouchothèque a déménagée 'the fly collection has moved', from a Québecois website), as opposed to just 3800 with 'be'. Since déménager is an intransitive verb denoting change of location, this result flies in the face of Sorace's (2000) semantically based auxiliary selection hierarchy (12), on which Bentley's account in (21b) is based: change of location intransitive predicates are predicted to select invariably 'be' cross-linguistically, in all systems in which the option is available. On the contrary, the assumption that déménager is unergative in spite of its semantics, and therefore shows the same behavior as manger in (3a), predicts selection of avoir under Perlmutter's rule (13). As for rester, as well as monter 'to rise', paraître 'to appear' and the other unaccusatives selecting auxiliary avoir in modern French - unlike arriver in (3b) and hence unexpectedly under rule (13) the reason why they have changed their auxiliation over time has been elucidated by La Fauci (2000: 30), through a refinement of Davies and Rosen's (1988) Predicate Union hypothesis. Those verbs have developed a structural innovation by which unaccusative $2 \rightarrow 1$ advancement now takes place at a deeper stratum than those displayed in the traditional 
relational diagrams I have used in this paper. Intuitively, unaccusativity has become more lexicalized in verbs like rester, losing part of the syntactic manifestations it preserves with verbs like arriver..$^{20}$

\subsection{Old Spanish}

Let us now move on to consider a further Romance example. Aranovich (2003) studied the gradual fading of the perfective auxiliary ser in the history of Spanish, concomitant with the progressive generalization of haber already considered in (2) and (4) above. Aranovich (2003: 11) convincingly argues that the gradual restriction in the use of ser was driven by semantic factors:

Semantic Displacement Hypothesis: In the diachronic development of the Spanish perfect auxiliary system, the closer the subject is to being prototypical patient, the longer the predicate resists the displacement of ser by haber.

Crucially, this gradual displacement is observed for both intransitives (with e.g. holgar 'to idle about', agentive and non-telic, not showing any instances of auxiliary ser after the 14th C. vs. morir 'to die', non-agentive and telic, which occurs with ser well into the 17th C.) and a subset of reflexive constructions (with e.g. vengarse 'to revenge', clearly agentive, taking auxiliary ser only until the 13th C. vs. arrepentirse 'to repent' still occurring with ser during the 17th C.). From this, Aranovich $(2003: 29,31)$ concludes that a semantic explanation of Romance auxiliation must replace the syntactic one made available by the unaccusative hypothesis: "Old Spanish data give support for a semantic analysis of split intransitivity [...] providing the blueprint of an argument to overcome Rosen's objections [cf. Rosen (1984), M.L.] against a semantic approach to split intransitivity in general".

Reflexives play a crucial role in this argument, since "The fact that reflexive verbs in Italian and French select the 'be' auxiliary is often offered as evidence for the unaccusative analysis of auxiliary selection (Rosen 1988; Legendre 1989; Perlmutter 1989; Grimshaw 1990), under the assumption that all reflexive verbs have subjects which are also objects at an underlying level of representation" (Aranovich 2003:29).

20 We cannot pursue this technical issue any further here, due to limitations of space. 
In Old Spanish, however, reflexives do not behave all alike, as only "a handful of quasi-reflexive verbs" take auxiliary ser, and this is also interpreted by Aranovich (2003:29) as further proof for his attack on syntactic unaccusativity:

The generalization that supports the unaccusative analysis in French and Italian [...] does not hold for Spanish, robbing the syntactic analysis of split intransitivity of crucial evidence for Old Spanish. [...] the distribution of the two perfect auxiliaries with reflexive verbs in Old Spanish supports a semantic analysis of split intransitivity, and gives evidence against a syntactic analysis.

To show that Aranovich's criticism of syntactic unaccusativity is indeed inconsistent, we have to introduce the structural representation of the predicates that Aranovich calls "quasi-reflexives". Those correspond to Burzio's (1986) “inherent reflexives" and to Rosen's (1981 [1988], 1982) "unaccusatives with retroherent advancement", as exemplified for Italian in $(23):^{21}$

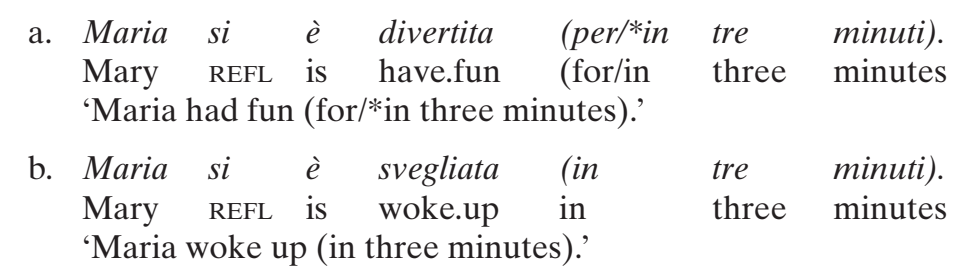

21 The anonymous referee invited me to compare Burzio's (1986) approach to unaccusativity with Perlmutter's. Burzio's book surely was influential, especially because Perlmutter's ideas on unaccusativity were not published yet at that time. However, his contribution basically boils down to an import of Perlmutter's hypothesis into the generative framework, as he himself acknowledges: "I must thank David Perlmutter for suggesting to me the single most important idea in this book, the one that he later termed the "Unaccusative Hypothesis"' (Burzio 1986: xiii). Whenever he elaborates on or departs from Perlmutter's original insights, the output is problematic. This is aptly exemplified by his use of 'ergative' instead of 'unaccusative', which Pullum (1988) showed to be a misnomer, a fact readily apparent from the table in (10) above, since the only argument of unaccusatives never gets ergative marking across languages. To quote just another example, what has been often referred to as 'Burzio's generalization', i.e. the generalization that only verbs which assign subject theta-role assign accusative case (Burzio 1986: 178), is strictly speaking a tautology, boiling down to the claim that only predicates that can be transitive are transitive: the property of assigning subject theta-role, in fact, individuates a set of verbs (transitives and unergatives) of which transitives are a subset, whereas the second property individuates just the subset of transitives. 


\begin{tabular}{|c|c|c|}
\hline 2 & & $\mathrm{P}$ \\
\hline 2,1 & & $\mathrm{P}$ \\
\hline 1 & & $\mathrm{P}$ \\
\hline 1 & $\mathrm{P}$ & Cho \\
\hline Maria & si è & divertita \\
\hline Maria & si è & svegliata \\
\hline
\end{tabular}

The representation in (23c) formalizes the following intuition: argumentally, divertirsi/svegliarsi are just like non-reflexive partire 'to leave', i.e. they are monovalent unaccusatives. ${ }^{22}$ The occurrence of reflexive $s i$ is determined by a purely syntactic process with no semantic import, viz. the loss of 2,1 multiattachment (cf. note 17) between the second and the third stratum. ${ }^{23}$ Consequently, in (23), unlike in, say, lavarsi 'to wash oneself' $((14 b))$, the occurrence of reflexive si has nothing to do with argument structure.

The structural subclass of retroherent reflexives is the only pronominal verb construction that admits (also) ser in Old Spanish, although already in competition with haber from the outset: ${ }^{24}$
a. A Maimino, que se era alçado con tierra de oriente to Maimino who REFL was rebelled with land of east 'To Maimino, who had rebelled with the Eastern lands.' (Primera crónica general, 13th C.)

b. Estonçe Rruy Diaz apriessa se fue levantado. then Ruy Diaz in.a.hurry REFL was risen 'And then Ruy Diaz had risen in a hurry.' (Mocedades de Rodrigo, 14th C.)

22 Note in passing that, within a system which is stable in this respect such as modern standard Italian (or Sardinian, examined in (20) above), the syntax of these verbs (as for auxiliation) is identical, whatever their Aktionsart. This is shown in (20) via the test in $\mathrm{x}$ time, by which svegliarsi qualifies as telic, whereas divertirsi qualifies as atelic.

23 Syntactic representations in RG consist of strata (two strata in (9b), (14a), three in $(9 a),(14 b)$, four in $(18 a-b)$ etc.). The initial stratum is defined by the grammatical relations assigned by the predicate, whereas subsequent strata come to differ from the first (in the cases discussed here) by the application of syntactic processes affecting some argument (e.g. unaccusative advancement in (9a), resolution of multiattachment in the second stratum in (14b), etc.) or by the insertion of a new predicate. In the latter case, clause structure divides into different P-sectors (cf. note 28).

24 All Old Spanish examples are Aranovich's. 
Over time, then, ser was replaced in these constructions through the same stages as for intransitives, with agentive (and, possibly, atelic) predicates taking auxiliary haber earlier. This is regarded as proof against the syntactic analysis, as is the fact that all other subclasses of reflexives invariably have auxiliary haber from the outset, as exemplified in (25). (25a) provides one example for direct transitive reflexives (whose structural representation was given above in (14b)), ${ }^{25}$ (25b) exemplifies indirect transitive reflexives (cf. (18b) above): ${ }^{26}$
a. no se hubieran destruido los unos a los otros not REFL had destroyed the ones to the others 'they would not have destroyed each other.'
(Alonso de Zorita, Relación de los Señores de la Nueva España,16th C.)
b. la palabra que entrambos a dos se habian dado the word that both to two REFL had given 'the word that each had given to the other.' (Cervantes, La española inglesa, 17th C.)

We are now in a position to refute Aranovich's pseudo-argument against a syntactic analysis of auxiliation (and unaccusativity). First of all, since retroherent unaccusatives (Aranovich's "quasi-reflexives") can be singled out from other reflexive constructions in terms of structural representation, as shown in (23), a syntactic analysis of the set of constructions in which auxiliary ser occurs in Old Spanish will prove possible, despite Aranovich's claims, if a structural generalization is available that refers to structural properties shared by plain and retroherent unaccusatives, as opposed to all other relevant syntactic constructions (i.e. the remaining reflexives, plus transitives and unergatives). This is indeed the case, as I will show in sections 5.3-5.4.

25 Example (25a) is actually an instance of a reciprocal construction. However, contrary to other languages in which dedicated morphosyntactic and/or morpholexical means convey the reflexive vs. reciprocal contrast, Romance clitic se/si-constructions serve both goals, the semantic difference being merely a matter of interpretation.

26 In Aranovich's data, no examples of indirect unergative reflexives -i.e., of the structural type (18a) - occur. 


\subsection{Old Florentine}

A glimpse at other medieval Romance dialects quickly reveals several instructive parallels for the Old Spanish situation. Thirteen century Florentine as reflected in Dante's oeuvre (cf. La Fauci 2004) is a case in point. Auxiliary essere 'be' occurs only in unaccusatives, plain and retroherent $((26 a-b))$, whereas auxiliary avere 'have' is found elsewhere (including the remaining reflexive constructions (26c-d)): (Note that the syntactic constructions are ordered along the same scale as for Sardinian in (17).). ${ }^{27}$

a. Fuggito ̀̀ ogni augel che 'l caldo segue (Rime c 27) fled is each bird that the heat follows unaccusative 'All birds that follow the heat have fled.'

b. io mi sarei brusciato

I me be.cond.1sg burnt

(If XVI 49)

'I would have burnt myself.'

c. la donna che [...] ci s' hae mostrata (Vn XXXVIII 3) the woman that us REFL has shown dir.trans. refl. 'The woman that showed herself to us.'

d. poscia che tanti specula fatti $s$, ha (Pd XxIx 143-4) after that so.many mirrors made REFL has indir. trans. refl. 'After that he has made (for himself) so many mirrors'

e. Ma $i$ Provenzai che fecer contra lui but the Provençals who made against him

non hanno riso (Pd VI 130-1)

not have laughed

unergative

'But the Provençals, who slandered him, did not laugh.'

This distribution of the auxiliaries is accounted for by the generalization in (27), slightly modified with respect to the original proposal by La Fauci (2004: 252):

Perfective auxiliation in Dante's Florentine

The perfective auxiliary is essere iff the final 1 :

i) is a 2;

ii) is not a P-initial 1.

Otherwise the perfective auxiliary is avere.

27 In quotations from Dante, the following abbreviations are used: If = 'Inferno', $\mathrm{Vn}=$ 'La vita nuova', $\mathrm{Pd}=$ 'Paradiso'. 
The rule is more restrictive than the one at work in modern Standard Italian (a diachronic successor of medieval Florentine) in that the final 1 is not only required to bear the 2 relation in some previous stratum (27i): it is also required not to be a P-initial subject, where "P-initial" means "in the initial stratum of a P[redicate]-sector' ${ }^{28}$ In a nutshell, modern Italian became less restrictive because, with the loss of condition (27ii), also direct (14b) and indirect reflexive constructions (18), whose final subject is a subject also argumentally (hence, P-initially), became candidates for selection of auxiliary essere, unlike in Dante's Florentine.

\subsection{Old Spanish compared with medieval central-southern Italo-Romance dialects}

Now it turns out that perfective auxiliation in Old Spanish is accounted for straightforwardly by assuming an auxiliary selection rule identical to (27). The only difference between Old Florentine and Old Castilian is that rule (27) applies categorically in the former, whereas in the latter its application appears variable from the outset, given that auxiliary haber seems to have crept into the domain of ser (viz. in unaccusative constructions, both plain and retroherent) ever since the earliest documentation of the language. Contrary to Florentine, then, the further diachronic evolution of Castilian proceeded towards a generalization of auxiliary haber which can be modeled by positing a transition from stage (28a) to (28b):

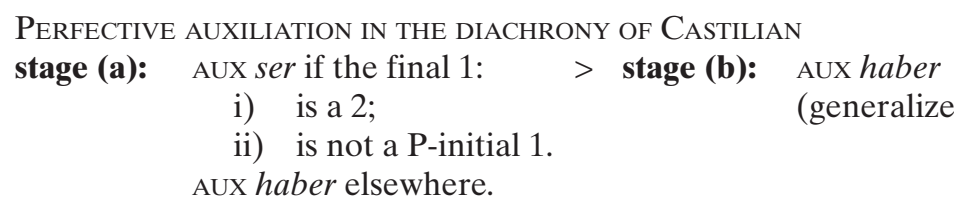

This transition between two different syntactic rules was part of a general typological drift - first described in these terms by La Fauci (1988) - in which Spanish was at the vanguard in shifting back from the ProtoRomance active/inactive alignment (best preserved nowadays in Standard Italian, see the features listed in note 13) to a more consistent accusa-

28 A P(redicate) sector is defined as the set of strata in which a given predicate bears the P-relation (cf. Davies and Rosen 1988: 57). 
tive alignment. As a matter of fact, Old Spanish still possessed several of the Proto-Romance active/inactive features, viz. double auxiliary choice, $n e$-pronominalization, past participle agreement etc. In modern Spanish, however, most of them were eventually lost.

Change in auxiliary choice, thus, must be placed against the background of this diachronic conspiracy. And indeed, during the transition (28a) $>$ (28b) semantic factors of the kind spotted by Aranovich came to play a crucial role. As a consequence, among unaccusatives (both plain and retroherent) loss of auxiliary ser occurred earlier for those predicates that were from the outset semantically closer to the semantic type that prevails in unergatives: agentive and non-telic.

Still, at the two ends of this transition stage, a syntactic analysis of (Old) Spanish perfective auxiliation is needed, contrary to Aranovich's claims. Without such an analysis (singling out, most notably, retroherent reflexives (23)-(24) among other subclasses of reflexive constructions), the domain in which variation and change in auxiliary choice are observed in medieval Spanish could not be appropriately defined in the first place. Again, unbiased consideration of the data confirms that syntax and semantics interact, and that it is not possible to reduce the former to the latter.

Italo-Romance dialect variation offers still closer parallels to the Old Spanish facts. Table (29) synthesizes the results of studies on perfective auxiliation on the best-documented Medieval Italo-Romance dialects from the Centre-South (viz. Old Romanesco, Old Neapolitan and Old Sicilian), carried out within Relational Grammar over the past 15 years (cf. respectively Formentin 2002: 236; Formentin 2001: 113; Vecchio 2006; La Fauci 1992: 70). ${ }^{29}$ (The abbreviations $\mathrm{E}$ and $\mathrm{H}$ indicate, as usual, categorical selection of the auxiliaries 'be' and 'have'; the brackets indicate that, for the construction at issue, the occurrences in the texts analyzed are very few, so that the result is not robust. In case there is variation, the percent of the occurrences of the more frequent auxiliary is given. $)^{30}$

29 This literature on related Romance dialects, which demonstrates the viability of a syntactic analysis for data extremely similar to the Old Spanish ones, is ignored by Aranovich.

30 Note further that the percents in (29) do not weigh all the same, given the differences in absolute figures. For Sicilian, La Fauci's (1992) text counts offer 319 occurrences of auxiliary $\mathrm{E}$ for plain unaccusatives vs. 57 occurrences of auxiliary $\mathrm{H}$, and 72 occurrences of auxiliary $\mathrm{H}$ vs. 13 of auxiliary $\mathrm{E}$ in retroherent unaccusatives. For Old Neapolitan, given the smaller corpora analyzed by Formentin (2001) and Vecchio (2006), the result is less robust: retroherent unaccusatives $17 \mathrm{E} / 14 \mathrm{H}$, direct transitive reflexives $19 \mathrm{H} / 3 \mathrm{E}$. 
a. unaccusatives

b. retroherent

c. dir. trans. refl.

d. indir. unerg.

e. indir. trans. refl.

f. unergatives

\begin{tabular}{|c|c|c|}
\hline i. Old Romanesco & ii. Old Neapolitan & iii. Old Sicilian \\
\hline E & $\mathrm{E}$ & $86 \% \mathrm{E}$ \\
${ } }$ & $55 \% \mathrm{E}$ & $85 \% \mathrm{H}$ \\
$\mathrm{E}$ & $86 \% \mathrm{H}$ & $\mathrm{H}$ \\
$\mathrm{nnn} \mathrm{H})$ & $\mathrm{H})$ & $\mathrm{H}$ \\
$\mathrm{H}$ & $\mathrm{H}$ & $\mathrm{H}$ \\
$\mathrm{H}$ & $\mathrm{H}$ & $\mathrm{H}$ \\
\hline
\end{tabular}

Old Romanesco displays a categorical distribution of the two auxiliaries across clause types. Much like in Sardinian, reflexives split into two subclasses (one selecting 'be', the other 'have'), although with a slightly different distribution.

Old Neapolitan and Old Sicilian, on the other hand, display a more restricted distribution of auxiliary $\mathrm{E}$ and show variation, with auxiliary $\mathrm{H}$ being optionally possible as well. This variation, crucially, is not chaotic but is localized just in the syntactic constructions - viz. $(29 b-c)$ for the former, $(29 a-b)$ for the latter - which come next on the scale and thus represent a natural extension of the domain of auxiliary $\mathrm{H}$. If variation were not observed, and only the majority variant were considered, Old Neapolitan and Old Sicilian would turn out to display the same system as the dialects in (30d) and (30e) respectively: (Table (30) elaborates on the result of the study of dialect variation in Romance auxiliation in Loporcaro 2007: 189, inserting medieval dialects into the picture.)

$\begin{array}{ll}\text { a. } & \text { Italian } \\ \text { b. } & \text { Sardinian } \\ \text { c. } & \text { Old Roman. } \\ \text { d. } & \text { Old Florent. } \\ \text { e. } & \text { Leccese } \\ \text { f. } & \text { Spanish }\end{array}$

\begin{tabular}{|c|c|c|c|c|c|}
\hline \multicolumn{5}{|c|}{ inactive } & active \\
\hline \multirow[t]{2}{*}{ unaccus. } & \multicolumn{4}{|c|}{ reflexive } & \multirow[t]{2}{*}{ trans./unerg. } \\
\hline & retr. & $\begin{array}{l}\text { dir. } \\
\text { trans. }\end{array}$ & $\begin{array}{l}\text { indir. } \\
\text { unerg. }\end{array}$ & $\begin{array}{l}\text { indir. } \\
\text { trans. }\end{array}$ & \\
\hline \multicolumn{5}{|l|}{$\mathrm{E}$} & $\mathrm{H}$ \\
\hline \multicolumn{5}{|l|}{ E } & $\mathrm{H}$ \\
\hline \multicolumn{5}{|l|}{ E } & $\mathrm{H}$ \\
\hline \multicolumn{5}{|l|}{ E } & $\mathrm{H}$ \\
\hline \multicolumn{5}{|l|}{ E } & $\mathrm{H}$ \\
\hline & & & & & $\mathrm{H}$ \\
\hline
\end{tabular}


Clearly, Old Neapolitan, with auxiliary $\mathrm{H}$ already prevailing in (29c) and almost balancing auxiliary $\mathrm{E}$ in $(29 \mathrm{~b}),{ }^{31}$ represents a transition stage between the Old Florentine (see (27) above) and the Leccese type, where auxiliary $\mathrm{H}$ was generalized throughout (including all reflexive constructions) except in plain unaccusatives. ${ }^{32}$

Old Sicilian, on the other hand, as for the behavior of reflexives, corresponds perfectly to Old Castilian: auxiliary 'be' still prevails in plain unaccusatives (29a), and, among reflexives, it is already confined within the structural class of retroherent constructions (29b). Here, into the bargain, 'be' already occurs in just a tiny minority of contexts. Clearly, this too qualifies as a transition phase on the way towards the final stage (28b) - or (30f) - that was reached by modern Sicilian as well as by modern Spanish.

Also these facts can be handled syntactically: a condition 'non-multiattached' (excluding all reflexives) is on its way to being added to rule (28a), thus creating a further intermediate step $(31 \mathrm{v})$ on the structural cline eventually leading to generalization of 'have':

31 Cennamo (1999: 322-325) advocates for the relevance of Sorace's (2000) ASH (cf. (12) above) for perfective auxiliation with unaccusatives in Old Neapolitan. She claims that auxiliary 'have' creeps into unaccusative constructions, in a way predicted by (12) (i.e., with non-core unaccusatives): e.g. ànno partuto 'they have left'. However, as demonstrated by Formentin (2001: 98-99), Cennamo's claim is based upon faulty textual readings and is impaired by lack of control over relevant variables. For instance, in the passage in (i) - drawn from the $15^{\text {th }}$ century Memories by Loise De Rosa, edited by Formentin (1998: 524) - partuto means 'divided' (transitive), not 'left', unlike implied by Cennamo:

(i) ànola presa et à(n)no partuto co lo re $\mathrm{Fe}(r)$ rante ly denare have taken and have shared with the king Ferrante the money et lo argento et ly pa(n)ne and the silver and the clothes

'They have taken it and have shared with king Ferrante money, silverware and clothes.'

Apart from this sort of misinterpretations, there are indeed genuine occurrences of auxiliary 'have' with unaccusatives. However, as shown by Formentin (2001: 94, 97, 99), these have nothing to do with Sorace's ASH, unlike implied by Cennamo, but are conditioned by verb mode, as they occur exclusively in past subjunctive and conditional (irrealis): e.g. averria insuto 'it would have come out'. A similar modal constraint, favoring 'have', was at work in Old Spanish too, as pointed out by Stolova (2006).

32 The same auxiliation system is observed today in several Romance dialects from the Alpine region (e.g. Engadinian and Surmiran, cf. Loporcaro 1998: 73, 2007: 187, 189). 
(31) Perfective auxiliation in six Romance varieties

The perfective auxiliary is 'be' if the final 1 :
i) is a 2;
ii) is the first 2 in the clause;
iii) is a P-initial 2;
iv) is a (P-initial) 2 ; not a P-initial 1 ;
v) is a (P-initial) 2 ; not multiattached. ${ }^{33}$
Otherwise the perfective auxiliary is avere.
[Italian]
[Logudorese Sardinian]
[Old Romanesco]
[Old Florentine]
[Leccese]
$[\text { Spanish }]^{34}$

This syntactic account enriches the one arrived at in Loporcaro (2007: 193), where data from medieval dialects are not considered. As shown in (29)-(30c-d) those ancient dialects indeed document structural options not anymore attested in present day Romance dialect varieties. On the whole, (31) portrays one aspect of the gradual fading of the active/inactive contrast, with the option originally selected only in active constructions (auxiliary 'have') gradually spreading to inactive ones, to finally conquer the very core thereof, plain unaccusatives.

\section{Conclusion}

In-depth analysis of variation in perfective auxiliation across time and space in Romance shows that euroversal (iv) ("use of 'have' and 'be' as auxiliaries") and euroversal (viii) ("accusativity", i.e. accusative alignment) in van der Auwera's (1998: 813) list are (partially) contradictory: differential 'have'/'be' perfective auxiliation in languages like Italian or French is a property which operates in terms of active/inactive rather than accusative/nominative alignment. Recognition of this fact was impeded by the circumstance that the properties displaying accusative alignment throughout SAE (basically, case marking and subject agreement on finite verb forms) can be observed straightforwardly (i.e., in a theory-neutral way) whereas active/inactive properties, in Romance (as well as elsewhere in European languages), can be pinned down only given the appropriate analytical procedure and the appropriate theoretical premises.

33 On the notion multiattachment cf. note 17 above.

34 In Spanish, actually, what used to be the elsewhere case (auxiliary haber) has generalized to become the only option. 
As for procedure, as argued in section 2, it is necessary not to single out 'have'-perfects, but to consider auxiliation in a systemic perspective, i.e. to consider 'have' and 'be' auxiliaries jointly, whenever they co-occur in one and the same language.

As for theory, a satisfactory analysis of Romance auxiliation proves possible under the assumption that unaccusativity is an autonomous syntactic phenomenon. Although this might be regarded as unnecessarily costly by some (e.g. Van Valin and La Polla 1997: 257), the analyses presented here show - like many other pieces of evidence - that there is no credible alternative to analyzing (Romance) auxiliation in terms of (syntactic) unaccusativity. Purported semanticist alternatives are either less economical, like Bentley and Eythórsson's (2003) account of auxiliation in modern standard Italian (discussed in section 4), or prove inconclusive and inconsistent upon closer inspection, like Aranovich's (2003) analysis of Old Spanish discussed in section 5.

The conclusions reached here on the specific topic of Romance auxiliary selection lead in turn to a more sophisticated view on the basic issue of alignment at the very core of SAE: accusativity, which surely is a major organizing principle of SAE syntax (reflected in case marking, subject agreement, basic SVO constituent order, etc.), turns out to be not quite so pervasive as it is commonly thought in the literature on linguistic typology discussed in section 2 .

\section{Abbreviations}

$\mathrm{ABS}=$ absolutive $; \mathrm{ACT}=$ active $; \mathrm{AUX}=($ perfective $)$ auxiliary $; \mathrm{COND}=$ condi tional; $\mathrm{DO}=$ direct object; $\mathrm{ERG}=$ ergative; $\mathrm{F}=$ feminine; INA = inactive; IO = indirect object; $\mathrm{M}=$ masculine; $\mathrm{NOM}=$ nominative; $\mathrm{REFL}=$ reflexive; $\mathrm{RG}=$ Relational Grammar; $\mathrm{SAE}=$ Standard Average European; $\mathrm{SG}=$ singular; TAM $=$ tense-aspect marker. 


\section{References}

Albano Leoni, Federico, Rosanna Sornicola, Eleonora Stenta Krosbakken and Carolina Stromboli (eds.)

2001 Dati empirici e teorie linguistiche. Atti del XXXIII Congresso della

Società di Linguistica Italiana, Napoli, 28-30 ottobre 1999. Rome:

Bulzoni.

Aldai, Gontzal

2000 Split ergativity in Basque: The pre-Basque antipassive-imperfective hypothesis. Folia Linguistica Historica 21:31-97.

Alexiadou, Artemis, Elena Anagnostopoulou and Martin Everaert.

2004 The Unaccusativity Puzzle. Explorations of the Syntax-Lexicon

Aranovich, Raúl

Interface. Oxford: Oxford University Press.

2003 The semantics of auxiliary selection in Old Spanish. Studies in Language 27: 1-37.

Bentley, Delia

2006 Split Intransitivity in Italian. Berlin: Mouton de Gruyter.

Bentley, Delia and Thórhallur Eythórsson

2003 Auxiliary selection and the semantics of unaccusativity. Lingua 114: 447-471.

Benveniste, Emile

1960 "Etre" et "avoir" dans leurs fonctions linguistiques. Bulletin de la

Bertinetto, Pier Marco Société de Linguistique de Paris 55:113-134.

1986 Tempo, aspetto e azione nel verbo italiano. Il sistema dell'indicativo. Firenze: Accademia della Crusca.

Bittner, Maria and Ken Hale

1996 The structural determination of case and agreement. Linguistic Inquiry 27: 1-68.

Blake, Barry J.

1990 Relational Grammar. London: Routledge.

Bossong, Georg

$1984 \quad$ Ergativity in Basque. Linguistics 22: 341-392.

Brettschneider, Gunter

1979 Typological characteristics of Basque. In: Frans Plank (ed.), Ergativity. Towards a Theory of Grammatical Relations, 371-384. London/

Burzio, Luigi

New York/Toronto/Sydney/San Francisco: Academic Press.

1986 Italian Syntax. A Government-Binding Approach. Dordrecht: Reidel.

Cennamo, Michela

1999 Inaccusatività tardo-latina e suoi riflessi in testi italiani antichi centro-meridionali. ZRPh 115: 300-331. 
Cennamo, Michela

2001 L'Inaccusatività in alcune varietà campane: teorie e dati a confronto. In: Federico Albano Leoni, Rosanna Sornicola, Eleonora Stenta Krosbakken and Carolina Stromboli (eds.), Dati empirici e teorie linguistiche, 427-453. Atti del XXXIII Congresso della Società di Linguistica Italiana, Napoli, 28-30 ottobre 1999. Rome: Bulzoni.

Cennamo, Michela and Antonella Sorace

2007 Auxiliary selection and split intransitivity in Paduan: Variation and lexical-aspectual constraints. In: Raúl Aranovich (ed.), Split Auxiliary Systems. A Cross-Linguistic Perspective, 65-99. Amsterdam: Benjamins.

Centineo, Giulia

1986 A lexical theory of auxiliary selection in Italian. Davis Working

Chomsky, Noam Papers in Linguistics 1: 1-35.

1981 Lectures on Government and Binding. Dordrecht: Foris.

Cocchi, Gloria

1995 La selezione dell'ausiliare. Padova: Unipress.

Comrie, Bernard

2005 Alignment of case marking. In: Martin Haspelmath, Matthew

S. Dryer, David Gil and Bernard Comrie (eds.), The World Atlas of Language Structures (WALS), 398-405. Cambridge: Cambridge

Dahl, Östen University Press.

2000 Tense and Aspect in the Languages of Europe. (Empirical Approaches to Language Typology, EUROTYP 6), 20-26. Berlin: Mouton de Gruyter.

Davies, William and Carol Rosen

1988 Unions as multi-predicate clauses. Language 64: 52-88.

Dixon, Robert M.W.

1972 The Dyirbal language of North Queensland. Cambridge: Cambridge

University Press.

Dixon, Robert M.W.

1994 Ergativity. Cambridge: Cambridge University Press.

Dowty, David

1991 Thematic proto-roles and argument selection. Language 67: 547619.

Drinka, Bridget

2003 Areal factors in the development of the European periphrastic perfect. Word 54: 1-38.

Drinka, Bridget

2007 The development of the HAVE perfect. Mutual influences of Greek and Latin. In: Raúl Aranovich (ed.), Split Auxiliary Systems. A Cross-Linguistic Perspective, 101-121. Amsterdam: Benjamins. 
Eguzkitza, Andolin and Georg A. Kaiser

1999 Postverbal subjects in Romance and German: Some notes on the unaccusative hypothesis. Lingua 109: 195-219.

Fava, Elisabetta (ed.)

1992 Proceedings of the XVII Meeting of Generative Grammar. Turin: Rosenberg \& Sellier.

Formentin, Vittorio (ed.)

1998 Loise de Rosa, Ricordi. 2 Volumes. Rome: Salerno.

Formentin, Vittorio

2001 L'ausiliazione perfettiva in antico napoletano. Archivio Glottologico Italiano 86: 79-117.

Formentin, Vittorio

2002 Tra storia della lingua e filologia: note sulla sintassi della «Cronica» d'Anonimo romano. Lingua e Stile 37: 203-250.

Friedmann, Naama, Gina Taranto, Lewis P. Shapiro and David Swinney

2008 The leaf fell (the leaf). The online processing of unaccusatives. Lin-

Grimshaw, Jane guistic Inquiry 39: 355-377.

1991 Argument Structure. Cambridge, Mass.: MIT Press.

Harris, Alice

1997 Review article of Dixon (1994). Language 73: 359-374.

Harris, Alice and Lyle Campbell

1995 Historical Syntax in Cross-Linguistic Perspective. Cambridge: Cambridge University Press.

Harris, Martin and Paolo Ramat (eds.)

1987 Historical Development of Auxiliaries. Berlin: Mouton de Gruyter.

Haspelmath, Martin

1998 How young is Standard Average European? Language Sciences 20: 271-287.

Haspelmath, Martin

2001 The European linguistic area: Standard Average European. In:

Martin Haspelmath, Ekkehard König, Wulf Oesterreicher and

Wolfgang Raible (eds.), Language Typology and Language Univer-

Heine, Bernd sals, 1492-1510. Berlin: Mouton de Gruyter.

1993 Auxiliaries. Cognitive Forces and Grammaticalization. Oxford:

Oxford University Press.

Heine, Bernd and Tanja Kuteva

2006 The Changing Languages of Europe. Oxford: Oxford University Press.

Kayne, Richard S.

1993 Toward a modular theory of auxiliary selection. Studia Linguistica 47:3-31.

Kempchinsky, Paula

1996 Perfective auxiliaries, possessives and existentials in Romance. In: 
Karen Zagona (ed.), Grammatical Theory and Romance Languages, Kishimoto, Hideki

135-144. LSRL 25. Amsterdam: Benjamins.

1996 Split intransitivity in Japanese and the unaccusative hypothesis. Language 72: 248-286.

Kuteva, Tanja

2001 Auxiliation. An Enquiry into the Nature of Grammaticalization. Oxford: Oxford University Press.

La Fauci, Nunzio

1988 Oggetti e soggetti nella formazione della morfosintassi romanza. Pisa: Giardini.

La Fauci, Nunzio

1992 Capitoli di morfosintassi siciliana antica: tassonomia dei costrutti medi e ausiliari perfettivi. In: Studi linguistici e filologici offerti a Girolamo Caracausi. Palermo: Centro di Studi Filologici e Linguistici Siciliani, 185-220 [also in Id., Forme romanze della funzione predicativa. Pisa: Edizioni ETS 2000, 41-73].

La Fauci, Nunzio

1994 Objects and Subjects in the Formation of Romance Morphosyntax.

La Fauci, Nunzio Bloomington, Indiana: IULC.

$2000 \quad$ Forme romanze della funzione predicativa. Pisa: ETS.

La Fauci, Nunzio

2004 Armonia differenziale dell'ausiliazione perfettiva nel volgare di Dante. In: Maurizio Dardano and Gianluca Frenguelli (eds.), SintAnt. La sintassi dell'italiano antico. Atti del Convegno internazionale di studi (Università “Roma Tre”, 18-21 settembre 2002), 237252. Rome: Aracne.

La Fauci, Nunzio and Michele Loporcaro

1993 Grammatical relations and syntactic levels in Bonorvese morphosyntax. In: Adriana Belletti (ed.), Syntactic Theory and the Dialects of Italy, 155-203. Turin: Rosenberg \& Sellier.

Ledgeway, Adam

1998 Avé(re) and esse(re) alternation in Neapolitan. In: Olga Fullana and Francesc Roca (eds.), Studies on the Syntax of Central Romance Languages, 123-147. Girona: University of Girona Press.

Legendre, Géraldine

1989 Unaccusativity in French. Lingua 79: 95-164.

Levin, Beth and Malka Rappaport Hovav 2005 Argument Realization. Cambridge: Cambridge University Press.

Lieber, Rochelle and Harald Baayen

1997 A semantic principle of auxiliary selection in Dutch. Natural Language and Linguistic Theory 15: 789-845. 
Lois, Ximena

1990 Auxiliary selection and past participle agreement in Romance. Probus 2: 233-255.

Loporcaro, Michele

1998 Sintassi comparata dell'accordo participiale romanzo. Turin: Rosenberg \& Sellier.

Loporcaro, Michele

2001 La selezione dell'ausiliare nei dialetti italiani: dati e teorie. In: Federico Albano Leoni, Rosanna Sornicola, Eleonora Stenta Krosbakken and Carolina Stromboli (eds.), Dati empirici e teorie linguis-

Loporcaro, Michele tiche, 455-476. Rome: Bulzoni.

2007 On triple auxiliation in Romance. Linguistics 45: 173-222.

Manandise, Esméralda

1987 AUX in Basque. In: Martin Harris and Paolo Ramat (eds.), Historical Development of Auxiliaries, 317-344. Berlin: Mouton de Gruyter.

Manzini, Maria Rita and Leonardo Maria Savoia

2005 I dialetti italiani e romanci. Morfosintassi generativa. 3 Volumes. Alessandria: Edizioni dell'Orso.

Manzini, Maria Rita and Leonardo Maria Savoia

2007 A Unification of Morphology and Syntax. Investigations into Romance and Albanian Dialects. London/New York: Routledge.

Mithun, Marianne

1991 Active/agentive case marking and its motivations. Language 67: $510-546$.

Palmer, Frank R.

1994 Grammatical Roles and Relations. Cambridge: Cambridge University Press.

Parisi, Domenico

1976 The past participle. Italian Linguistics 1:77-106.

Perlmutter, David M.

1978 Impersonal passives and the unaccusative hypothesis. Proceedings of the 4th Annual Meeting of the Berkeley Linguistic Society: 157189.

Perlmutter, David M.

1989 Multiattachment and the unaccusative hypothesis: The perfect auxiliary in Italian. Probus 1: 63-119.

Perlmutter David M. and Paul M. Postal

1983 Some proposed laws of basic clause structure. In: David M. Perlmutter, (ed.), Studies in Relational Grammar 1, 81-128. Chicago/London: Chicago University Press.

Plank, Frans (ed.)

1979 Ergativity. Towards a Theory of Grammatial Relations. London/ New York/Toronto/Sydney/San Francisco: Academic Press. 
Pullum, Geoffrey

1988 Citation etiquette beyond thunderdome. Natural Language and

Ramat, Paolo

Linguistic Theory 6: 579-588.

1987 Introductory paper. In: Martin Harris and Paolo Ramat (eds.), Historical Development of Auxiliaries, 3-19. Berlin: Mouton de Gruyter.

Rappaport Hovav, Malka and Beth Levin

2000 Classifying single argument verbs. In: Peter Coopmans, Martin Everaert and Jane Grimshaw (eds.), Lexical Specification and Insertion, 269-304. Amsterdam: Benjamins.

Rosen, Carol

1981 [1988] The Relational Structure of Reflexive Clauses. New York: Gar-

Rosen, Carol land [PhD diss., Harvard University 1981].

1982 The unaccusative hypothesis and the 'inherent clitic' phenomenon in Italian. Chicago Linguistic Society 18: 530-541.

Rosen, Carol

1984 The interface between semantic roles and initial grammatical relations. In: David M. Perlmutter and Carol Rosen (eds.), Studies in Relational Grammar 2,38-77. Chicago/London: Chicago University Press.

Rosen, Carol

1990 Rethinking Southern Tiwa: The geometry of a triple-agreement lan-

Rosen, Carol guage. Language 66: 669-713.

1997 Auxiliation and serialization: on discerning the difference. In: Alex Alsina, Joan Bresnan and Peter Sells (eds.), Complex Predicates, 175-202. Stanford, CA: Center for the Study of Language and Information.

Sapir, Edward

1917 Review of C.C. Uhlenbeck. 1916. Het passieve karakter van het verbum transitivum of van het verbum actionis in talen van NoordAmerika. Verslagen en Mededeelingen der Koninklijke Akad. van Wetenschappen, Afd. Letterkunde, Vijfde Reeks, Tweede Deel, 187216, International Journal of American Linguistics 1, 82-86 [repr. in The collected works of Edward Sapir, Volume 5, American Indian Languages, 1. William Bright (ed.), 69-74. Berlin: Mouton de Gruyter 1990].

Sorace, Antonella

2000 Gradients in auxiliary selection with intransitive verbs. Language 76: 859-890.

Sorace, Antonella

2008 Psycholinguistic signatures of gradient auxiliary selection and models of the syntax-lexicon interface. Paper given the 42th Annual Con- 
ference of the Società di Linguistica Italiana, Pisa, September 25-27, 2008.

Squartini, Mario

1998 Verbal Periphrases in Romance: Aspect, Actionality and Grammaticalization. Berlin: Mouton de Gruyter.

Squartini, Mario and Pier Marco Bertinetto

2000 The simple and compound past in Romance languages. In: Östen

Dahl (ed.), Tense and Aspect in the Languages of Europe. (Empirical Approaches to Language Typology, EUROTYP 6), 403-439. Berlin: Mouton de Gruyter.

Stammerjohann, Harro (ed.)

1986 Tema-Rema in Italiano. Tübingen: Narr.

Stolova, Natalya I.

2006 Split intransitivity in Old Spanish: irrealis and negation factors. Revue roumaine de linguistique (Romanian review of linguistics) 51: 301-320.

Thieroff, Rolf

2000 On the areal distribution of tense-aspect categories in Europe. In: Östen Dahl (ed.), Tense and Aspect in the Languages of Europe. (Empirical Approaches to Language Typology, EUROTYP 6), 265305. Berlin: Mouton de Gruyter.

Ura, Hiroyuki

2000 Checking Theory and Grammatical Functions in Universal Grammar. Oxford: Oxford University Press.

van der Auwera, Johan

1998 Conclusion. In: Johan van der Auwera (ed.), Adverbial Constructions in the Languages of Europe. (Empirical Approaches to LanVan Hout, Angeliek guage Typology, EUROTYP 3), 20-23. Berlin: Mouton de Gruyter.

2004 Unaccusativity as telicity checking. In: Artemis Alexiadou, Elena Anagnostopoulou and Martin Everaert (eds.), The Unaccusativity Puzzle. Explorations of the Syntax-Lexicon Interface, 60-158. Oxford: Oxford University Press.

Van Valin, Robert

1990 Semantic parameters of split intransitivity. Language 66:221-260.

Van Valin, Robert and Randy La Polla

1997 Syntax: Structure, Meaning and Function. Cambridge: Cambridge University Press.

Vecchio, Paola

2006 L'ausiliazione perfettiva in napoletano. Studio di sintassi diacronica. $R L R$ 70: 53-94.

Whorf, Benjamin Lee

1956 Language, Thought, and Reality. Selected Writings of Benjamin Lee Whorf. Edited by J.B. Carroll. Cambridge, Mass.: MIT Press/New York: Wiley. 


\section{Zagona, Karen}

1996 Grammatical Theory and Romance Languages. LSRL 25. Amsterdam: Benjamins 